\title{
Different adhesins for type IV collagen on Candida albicans: identification of a lectin-like adhesin recognizing the $7 S$ (IV) domain
}

\author{
Ruth Alonso, ${ }^{1}$ Inés Llopis, ${ }^{1}$ Consuelo Flores, ${ }^{2}$ Amelia Murgui ${ }^{1}$ \\ and Joaquín Timoneda ${ }^{1}$
}

Author for correspondence: Joaquín Timoneda. Tel: +34 6 3983189. Fax: +34 63864917.

e-mail: Joaquin.Timoneda@uv.es

1 Secció Departamental de Bioquímica i Biologia Molecular, Facultat de Farmacia, Universitat de Valencia, Avda Vicent A. Estellés, $s / n, 46100$ Burjassot (València), Spain

2 Departamento de Bioquímica, Facultad de Estomatología, Benemérita Universidad autónoma de Puebla, Mexico

\begin{abstract}
Adherence of the opportunistic pathogen Candida albicans to basement membrane (BM) proteins is considered a crucial step in the development of candidiasis. In this study the interactions of $C$. albicans yeast cells with the three main domains of type IV collagen, a major BM glycoprotein, were analysed. $C$. albicans adhered to the three immobilized domains by different mechanisms. Adhesion to the $\mathbf{N}$-terminal cross-linking domain (7S) required the presence of divalent cations, whereas interaction with the central collagenous domain (CC) was cation-independent. Recognition of the C-terminal noncollagenous domain (NC1) was partially cation-dependent. Binding inhibition assays with the corresponding domains in soluble form showed that these interactions were specific. Both $\mathrm{Ca}^{2+}$ and $\mathrm{Mg}^{2+}$ promoted adhesion to the $7 \mathrm{~S}$ domain and the interaction was completely abolished by EDTA. Treatment of the $7 \mathrm{~S}$ domain, or its subunits, with $\mathrm{N}$-glycosidase $\mathrm{F}$ reduced yeast binding by approximately $\mathbf{7 0} \%$. Moreover, several sugars known to be part of the $\boldsymbol{N}$-linked oligosaccharide chains of collagen IV inhibited adhesion to immobilized 7S; $N$ acetylglucosamine, L-fucose and methylmannoside caused a similar inhibition whereas $\mathbf{N}$-acetyllactosamine was a more effective inhibitor. In contrast, glucose, galactose, lactose or heparan sulfate did not affect yeast binding. Combinations of the inhibitory sugars at suboptimal inhibition concentrations did not reduce $C$. albicans adhesion more than the individual sugars, pointing to a single lectin as responsible for the interaction. These results taken together show that $C$. albicans utilizes several adhesins for interacting with type IV collagen, and that at least one of them is a lectin which recognizes the 7S(IV) oligosaccharide residues as its receptor.
\end{abstract}

Keywords: yeast, basement membrane, adhesion, oligosaccharide binding

\section{INTRODUCTION}

Candida albicans is an opportunistic fungal pathogen which normally inhabits the oral cavity, respiratory and intestinal tracts, and vaginal cavity of humans and animals, as a minor component of the microbial flora. If given an opportunity, partly through depletion of host innate and specific immune defences, this micro-

\footnotetext{
Abbreviations: $\mathrm{BM}$, basement membrane; $\mathrm{CC}$, central collagenous domain of type IV collagen; ConA, concanavalin $\mathrm{A}$; ECM, extracellular matrix ; LBM, anterior lens capsule basement membrane; NC1, C-terminal noncollagenous domain of type IV collagen; 7S, $\mathrm{N}$-terminal 7S domain of type IV collagen.
}

organism causes the development of local or systemic infections and is one of the leading agents of invasive fungal disease in premature infants, diabetics, surgical patients, and hosts with human immunodeficiency virus infection or other immunosuppressed conditions. Although several factors may contribute to the pathogenesis of C. albicans infection, a critical event is thought to be the adherence of the micro-organism to host epithelial and endothelial cells, and to their underlying basement membrane (BM) or extracellular matrix (ECM) (Cutler, 1991; Chaffin et al., 1998; Fukazawa \& Kagaya, 1997; Klotz, 1994; Sundstrom, 1999; VázquezTorres \& Balish, 1997). As a consequence, much work has been done regarding the types, characteristics and 
mechanisms of this adhesion. However, it is not clear if all the existing interactions have been identified, and the roles played by these various interactions in the development of infection are even less clear.

Collagen IV is an exclusive and major glycoprotein of BMs. Its monomeric structure is formed by a triple helix of three $\alpha$-chains and three clearly distinct domains can be differentiated: a central collagenous (CC) domain consisting of a triple helix containing numerous short interruptions to the Gly-X-Y sequence, the C-terminal non-collagenous (NC1) domain and the $\mathrm{N}$-terminal (7S) domain. Individual (monomeric) collagen IV molecules assemble to form the sheet-like network which constitutes the basic structure of BMs. Several modes of interaction are known. Collagen IV monomers associate at the NC1 domains forming dimers and at the $7 \mathrm{~S}$ domains forming tetramers. These associations are sometimes stabilized by disulfide and other non-reducible covalent bonds. In addition to these end-to-end interactions, the flexible interrupted triple-helical domains intertwine and interact with NC1 domains to form supercoiled structures (Hudson et al., 1993). This collagen IV network binds to laminin either directly through its major triple-helical domain or indirectly through an entactin bridge. Moreover, both laminin and entactin also bind directly heparan sulfate proteoglycan, allowing the association of the major constituents of BMs (Martin \& Timple, 1987; Linblom \& Paulsson, 1996). Each chain in the collagen molecule is glycosylated, containing about 50 hydroxylysine-linked disaccharide units along the triple helix and one asparagine-linked carbohydrate unit near the $\mathrm{N}$ terminus, at the 7S domain (Langeveld et al., 1991; Nayak \& Spiro, 1991; Spiro \& Fukushi, 1969). This Asn-linked oligosaccharide occurs predominantly in the form of complex tri- and biantennary units with some tissueand species-dependent variations (Langeveld et al., 1991; Nayak \& Spiro, 1991).

Specific interactions of collagen type IV with a great variety of cell types, including extracellular and intracellular pathogens, have been reported (Adini \& Warburg, 1999; Bouchara et al., 1996; Bromley \& Donaldson, 1996; Gil et al., 1996; Klotz, 1990). These interactions promote cell adhesion, cell differentiation or cell proliferation (Ogata, 1998; Toda et al., 1995), and may influence the pathogenicity of several microorganisms. As an example, Aspergillus fumigatus spores and conidia bind specifically to type IV collagen and other ECM proteins, suggesting that the exposure of BMs that occurs in some diseases, such as asthma, may facilitate the colonization of the corresponding tissue by the micro-organism (Bromley \& Donaldson, 1996; Gil et al., 1996). Similarly, the spores and mother cells of germ tubes of the human pathogenic fungus Rhizopus oryzae adhere readily to immobilized type IV collagen or laminin (Bouchara et al., 1996). Adhesion of C. albicans to collagen IV has also been described. The yeast adheres more avidly to collagen IV than to other BM components such as laminin, fibronectin or several glycosaminoglycans (Klotz, 1990).
As far as is known, attachment of cells to collagen IV is mediated mainly by receptors which belong to the $\beta_{1}$ subgroup of the integrin family, namely $\alpha_{1} \beta_{1}, \alpha_{2} \beta_{1}$ and $\alpha_{3} \beta_{1}$ (Dickerson et al., 1999; Setty et al., 1998). The integrins interact at several sites along the whole collagen molecule, resulting in a single integrin having more than one binding site or a single collagen molecule being recognized by several integrins (Knight et al., 2000; Setty et al., 1998). Recently, it has been shown that a small peptide of the NC1 domain of the $\alpha 3$ (IV) chain interacts specifically with the CD47/integrin-associated protein and integrin $\alpha_{\mathrm{v}} \beta_{3}$ (Shahan et al., 1999). Similarly, Petitclerc et al. (2000) have described endothelial cell adhesion to the NC1 domain of the $\alpha 2$ (IV) chain mediated by the integrins $\alpha_{\mathrm{V}} \beta_{3}$ and $\alpha_{\mathrm{V}} \beta_{5}$. Integrin-like adhesins for collagen I, fibronectin, fibrinogen, vitronectin and the $\mathrm{iC} 3 \mathrm{~b}$ complement fragment have also been described in the most pathogenic Candida spp. (Gale et al., 1996; Klotz et al., 1993, 1994; Spreghini et al., 1999). Moreover, this fungus interacts with epithelial and endothelial cell-surface glycolipids or glycoproteins through lectin-like adhesins with specificity for their oligosaccharide moieties containing L-fucose, $\mathrm{N}$-acetylglucosamine, $\mathrm{N}$-acetylgalactosamine or lactose residues arranged in particular stereochemical configurations (Fukazawa \& Kagaya, 1997). However, although it is well established that C. albicans adheres to collagen IV, no specific receptor (adhesin) for this molecule has been characterized so far.

In the present work we studied the adhesion of $C$. albicans to the three main domains of type IV collagen and, by analysing cation dependence, the effect of Asnlinked carbohydrate removal and the inhibition caused by several sugars, we showed that (1) C. albicans yeast cells possess several adhesins which interact with collagen IV, and (2) the oligosaccharide residues present in $7 \mathrm{~S}$ domain of collagen IV function as receptors for at least one of these adhesins.

\section{METHODS}

Organism and growth conditions. C. albicans strain ATCC 26555 was used in this study. The organism was maintained at $4{ }^{\circ} \mathrm{C}$ by periodic transfer to Sabouraud dextrose agar (Becton Dickinson Microbiology Systems). For assays, a loopful of yeast was propagated in modified Lee's medium (Lee et al., 1975 ) for $16 \mathrm{~h}$ at $28^{\circ} \mathrm{C}$ with shaking. Yeasts were then washed by centrifugation in the appropriate buffer, resuspended and counted.

Isolation of BM. Anterior lens capsule BM (LBM) was prepared from bovine lenses according to a method described by Peczon et al. (1982) with some modifications. Bovine lenses were collected from a local slaughterhouse (Mercavalencia) and frozen immediately in dry ice. BMs were excised from partially thawed lenses with a scalpel, washed with an ice-cold $0.9 \% \mathrm{NaCl}$ solution containing the protease inhibitors $\mathrm{N}$ ethylmaleimide $(4 \mathrm{mM})$, benzamidine/ $\mathrm{HCl}(5 \mathrm{mM})$, EDTA $(10 \mathrm{mM}), 6$-aminohexanoic acid $(25 \mathrm{mM})$, PMSF $(1 \mathrm{mM})$ and sodium azide $(0.025 \%)$, and freed from attached cells by sonication in the protease inhibitor solution. BM suspension was kept in an ice bath and sonic disruption was accomplished 
in five 1 min bursts with 30 s delay between bursts to allow the suspension to cool. After an additional sonication step in $0.025 \%$ sodium azide, BMs were stored at $-30{ }^{\circ} \mathrm{C}$.

Purification of type IV collagen 7S and NC1 domains. The 7S and NC1 domains were isolated from LBM as described by Langeveld et al. (1988). LBM was digested with bacterial collagenase (high-purity collagenase, type VII; Sigma) at $37^{\circ} \mathrm{C}$ for $48 \mathrm{~h}$ in a digestion buffer consisting of $50 \mathrm{mM}$ HEPES $\mathrm{pH} 7 \cdot 5,10 \mathrm{mM} \mathrm{CaCl}_{2}$ and the above-mentioned protease inhibitors. This treatment solubilizes the NC1 domain with retention of hexamer structure and the $7 \mathrm{~S}$ domain with retention of dodecamer structure, but destroys the triplehelical domain. Both domains were then purified from the solubilized material under associative conditions using anionexchange and gel filtration chromatography. After dialysis

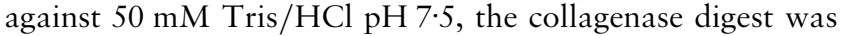
loaded onto a DEAE-52 cellulose anion-exchange column $(8 \times 2.8 \mathrm{~cm}$; Whatman $)$ and eluted with dialysis buffer. The unbound fraction, which contained both domains, was concentrated by ultrafiltration through a PM-10 membrane filter (Amicon) and applied to a Sephacryl S 300 column $(105 \times 2.9 \mathrm{~cm})$ (Amersham Pharmacia Biotech) equilibrated in $50 \mathrm{mM}$ Tris/HCl pH 7.5, $150 \mathrm{mM} \mathrm{NaCl}, 0.025 \%$ sodium azide. The proteins were eluted with the equilibration buffer at a flow rate of $30 \mathrm{ml} \mathrm{h}^{-1}$ and collected in fractions of $2.5 \mathrm{ml}$. The 7S and NC1 hexamer domains eluted in the first and second peak, respectively. Both peaks were concentrated with an Amicon PM-10 membrane filter and stored at $-30{ }^{\circ} \mathrm{C}$. Unless otherwise indicated, the process was carried out at room temperature. Part of the preparations were dialysed extensively against ultrapure water and lyophilized. The purity of the preparations was checked by immunoblotting using polyclonal specific antibodies against each domain (Bejarano et al., 1989). The antibodies were a generous gift of Professor B. G. Hudson (University of Kansas Medical Center, USA).

Isolation of CC triple-helical domain. The CC domain of type IV collagen was isolated from LBM by limited pepsin digestion (Hudson et al., 1995). This treatment excises fragments of the CC domain maintaining the triple helical structure and destroys the NC1 domain. LBMs were dispersed in $0.5 \mathrm{M}$ acetic acid (5 mg wet $\mathrm{wt} \mathrm{ml}^{-1}$ ) and incubated with pepsin (Sigma) at a ratio of $1: 10$ (pepsin: substrate) for $48 \mathrm{~h}$ at $4^{\circ} \mathrm{C}$. Insoluble material was removed by centrifugation and the collagenous fragments were precipitated from the supernatant with $20 \% \mathrm{NaCl}$. The pellet was dissolved in $0.5 \mathrm{M}$ acetic acid and precipitated again with $\mathrm{NaCl}$. The pellet was redissolved in $0.5 \mathrm{M}$ acetic acid and dialysed against the same solvent. The isolated CC domain was frozen at $-30{ }^{\circ} \mathrm{C}$ until used. All steps were performed at $4{ }^{\circ} \mathrm{C}$. The purity of the preparation was tested by developing electroblotted peptides with a polyclonal anti-type IV collagen antibody (kindly provided by Professor B. G. Hudson, University of Kansas Medical Center, USA). This antibody has been raised against reduced and alkylated collagen IV and reacts primarily with the CC triple-helical region. However, it also detects the monomeric $(\sim 25 \mathrm{kDa})$ and dimeric $(\sim 50 \mathrm{kDa})$ subunits of the NC1 domain, but does not recognize the $7 \mathrm{~S}$ domain (Bejarano et al., 1988). Protein concentrations were determined by the bicinchoninic acid protein assay method (Smith et al., 1985) (Pierce) or by the $A_{280}$ of the samples.

Purification of 7S domain subunits. Subunits of the $7 \mathrm{~S}$ domain were obtained from the reduced and carboxyamidomethylated domain by preparative SDS-PAGE with the buffer system of Laemmli (1970). One milligram of reduced, carboxyamidomethylated domain was diluted in Laemmli sample buffer and loaded onto a $14 \%$ acrylamide cylindrical gel $(0 \cdot 7 \times 11 \mathrm{~cm})$. Electrophoresis was conducted at $200 \mathrm{~V}$ constant voltage using a Bio-Rad Mini Prep Cell. A solution consisting of $0.025 \mathrm{M}$ Tris, $0.192 \mathrm{M}$ glycine $\mathrm{pH} 8.3$ was used as elution buffer at a flow rate of $6 \mathrm{ml} \mathrm{h}^{-1}$. When bromophenol blue started to elute from the gel, fractions of $0.75 \mathrm{ml}$ were collected and their $A_{280}$ values measured. The absorbance peaks were analysed by concanavalin A (ConA)-blotting and the fractions of interest were pooled, concentrated with an Amicon ultrafree- 4 concentrator and stored at $-30{ }^{\circ} \mathrm{C}$.

Reduction and alkylation of $7 \mathrm{~S}$ domain. $7 \mathrm{~S}$ disulfide bridges were reduced and thiol groups carboxyamidomethylated as described by Aitken \& Learmonth (1996). Lyophilized 7S domain was dissolved in $0.2 \mathrm{M}$ Tris $/ \mathrm{HCl} \mathrm{pH} 7 \cdot 5$ containing $6 \mathrm{M}$ guanidine $\left(1 \mathrm{mg} \mathrm{ml}^{-1}\right)$ and reduced by incubating with $0.1 \mathrm{M}$ (final concentration) mercaptoethanol for $3 \mathrm{~h}$ at $35^{\circ} \mathrm{C}$ under $\mathrm{N}_{2}$. Thiol groups were then carboxyamidomethylated with $2 \mathrm{M}$ (final concentration) iodoacetamide at $37^{\circ} \mathrm{C}$ for $30 \mathrm{~min}$ in the dark. Excess reagents were removed by dialysis against $50 \mathrm{mM}$ Tris $/ \mathrm{HCl} \mathrm{pH} 7 \cdot 5$.

Deglycosylation with $\mathbf{N}$-glycosidase F. Carboxyamidomethylated $7 \mathrm{~S}$ domain or its purified subunits were dissolved in $125 \mathrm{mM}$ Tris $/ \mathrm{HCl} \mathrm{pH} \mathrm{7.5,} 10 \mathrm{mM}$ EDTA, $1 \%$ (v/v) Triton $\mathrm{X}-100$ at a final concentration of about $0.25 \mathrm{mg} \mathrm{ml}^{-1}$. Ten units of peptide $N$-glycosidase F (EC 3.5.1.52; Roche Molecular Biochemicals) were added per ml protein solution and digestion was performed at $30^{\circ} \mathrm{C}$ for $18 \mathrm{~h}$. The enzyme was inactivated by heating for $5 \mathrm{~min}$ at $100{ }^{\circ} \mathrm{C}$ and the released oligosaccharides were removed by gel centrifugation (Penefsky, 1977) on Sephadex G 50 fine (Amersham Pharmacia Biotech) equilibrated in Dulbecco's phosphate buffered saline (DPBS) without $\mathrm{CaCl}_{2}$ and $\mathrm{MgCl}_{2}$ (modified DPBS) (Biowhittaker). As controls, equal amounts of each peptide were processed in parallel but without $\mathrm{N}$-glycosidase $\mathrm{F}$ added. The efficiency of deglycosylation was checked by ConA-blotting.

Peroxidase labelling of yeasts. Candida yeast cells were surface-labelled with ExtrAvidin-peroxidase conjugate (Sigma) according to Peñalver et al. (1996) with minor modifications. Yeast cells were suspended in $100 \mathrm{mM}$ sodium bicarbonate $\mathrm{pH} 8$ containing $1 \mathrm{mg} \mathrm{N}$-hydroxysuccinimidobiotin $\mathrm{ml}^{-1}$. N-hydroxysuccinimidobiotin was previously dissolved in dimethylformamide. The suspension was incubated for $1 \mathrm{~h}$ at $28^{\circ} \mathrm{C}$ with shaking and the cells were then washed three times with $50 \mathrm{mM}$ sodium phosphate $\mathrm{pH} 6$ and twice with $10 \mathrm{mM}$ Tris $/ \mathrm{HCl} \mathrm{pH} 7 \cdot 4,0 \cdot 9 \% \mathrm{NaCl}$. Biotinylated cells were resuspended in a 1:100 dilution of ExtrAvidinperoxidase conjugate in $10 \mathrm{mM}$ Tris $/ \mathrm{HCl} \mathrm{pH} \mathrm{7.5,0.9 \%} \mathrm{NaCl}$, $3 \%$ BSA. After incubating for $1 \mathrm{~h}$ at $28{ }^{\circ} \mathrm{C}$, the labelled cells were washed three times with modified DPBS or DPBS, and used for adherence assays. For cation-dependent adherence assays, the labelled cells were washed with $50 \mathrm{mM}$ HEPES $\mathrm{pH} 7 \cdot 5$.

For testing the effect of proteolytic treatment on yeast cell adherence, $2.5 \times 10^{9}$ yeast cells were incubated with $300 \mathrm{N \alpha}$ benzoyl-L-arginine ethyl ester (BAEE) units of trypsin in $1 \mathrm{ml}$ DPBS at room temperature for $30 \mathrm{~min}$. Yeast cells incubated with only buffer or with trypsin heated at $100{ }^{\circ} \mathrm{C}$ for $10 \mathrm{~min}$ were used as controls. After washing three times with $0 \cdot 1 \mathrm{M}$ sodium bicarbonate $\mathrm{pH} 8 \cdot 0$, the incubated cells were peroxidase-labelled as described above and used for adherence assays.

Adherence assays. C. albicans adherence to immobilized proteins was quantified in 96-well flat-bottom microtitre plates (Maxi-sorp immunoplate; Nunc). The plates were 
coated by adding $100 \mu \mathrm{l}$ assayed protein dissolved, unless otherwise indicated, in modified DPBS and incubating at $4{ }^{\circ} \mathrm{C}$ for $16 \mathrm{~h}$. Afterwards, the wells were washed with modified DPBS and the unoccupied sites at the plastic surface were blocked with modified DPBS $/ 1 \%$ BSA for $1 \mathrm{~h}$ at $37^{\circ} \mathrm{C}$. After washing three more times with modified DPBS, $10^{6}$ peroxidase-labelled yeast cells suspended in $100 \mu \mathrm{l}$ modified DPBS or DPBS were added to each well and incubated for $1 \mathrm{~h}$ at $37^{\circ} \mathrm{C}$. Unbound cells were removed by washing three times with modified DPBS or DPBS and adhered cells were then quantified by adding $100 \mu \mathrm{l}$ peroxidase substrate solution and measuring enzyme activity. When the effect of each cation concentration was assayed, $50 \mathrm{mM}$ HEPES pH $7 \cdot 5$ containing the indicated $\mathrm{CaCl}_{2}$ or $\mathrm{MgCl}_{2}$ concentrations substituted for DPBS throughout the whole experiment. O-Phenylenediamine dissolved in $50 \mathrm{mM}$ phosphate/citrate buffer $\mathrm{pH} 7.5$ was used as the chromogenic substrate. Enzyme reaction was stopped with $25 \mu \mathrm{l} 3 \mathrm{M} \mathrm{H}_{2} \mathrm{SO}_{4}$ per well and colour intensity was measured at $492 \mathrm{~nm}$ with an automated plate reader (Multiscan MS; Labsystem). Wells processed in the same way but coated only with modified DPBS were used as blanks and their $A_{492}$ values were subtracted from those of the other wells. As a reference, $10^{6}$ labelled cells resuspended in $100 \mu \mathrm{l}$ peroxidase substrate solution were added to untreated wells and their $A_{492}$ values taken as $100 \%$ adherence. Results are presented as percentage absorbance of the reference values. Each determination was done in triplicate. Laminin from mouse EHS-tumour and fibronectin from human plasma were supplied by Roche Molecular Biochemicals, and type IV collagen from EHS-tumour by Sigma.

Immuno- and ConA-blotting. SDS-PAGE was carried out in a miniVE vertical electrophoresis unit (Hoefer Scientific Instruments) with the discontinuous buffer system of Laemmli (1970). The proteins, unless otherwise specified, were separated in 4-20\% acrylamide gradient gels and kaleidoscope prestained standards from Bio-Rad were used for their electrophoretic molecular mass estimation. The gels were transferred electrophoretically to nitrocellulose paper (Amersham Pharmacia Biotech) at $150 \mathrm{~mA}$ constant current for $14 \mathrm{~h}$ at $4{ }^{\circ} \mathrm{C}$ with the buffer system of Towbin et al. (1979). The nitrocellulose papers were then immersed for $1 \mathrm{~h}$ at room temperature in a blocking solution consisting of $10 \mathrm{mM}$ Tris $/ \mathrm{HCl} \mathrm{pH} 8 \cdot 0,150 \mathrm{mM} \mathrm{NaCl}, 0 \cdot 05 \%$ Tween 20 (TBST) and $5 \%(\mathrm{w} / \mathrm{v})$ skimmed milk. After washing with TBST, the blots were incubated with the corresponding antibodies adequately diluted in TBST for $2 \mathrm{~h}$ at room temperature. The nitrocellulose membranes were washed three times with TBST, reincubated for $1 \mathrm{~h}$ at room temperature with alkalinephosphatase-conjugated goat anti-rabbit IgG (Promega) at a dilution of 1:7500 in TBST, and washed three more times with TBST. Alkaline phosphatase activity was developed with $33 \mathrm{mg}$ nitro blue tetrazolium and $16.5 \mathrm{mg}$ 5-bromo-4-chloro3 -indolyl phosphate (both obtained from Sigma) dissolved in $100 \mathrm{ml} 100 \mathrm{mM}$ Tris/HCl pH 9.5, $100 \mathrm{mM} \mathrm{NaCl}, 5 \mathrm{mM}$ $\mathrm{MgCl}_{2}$. NBT and BCIP were previously dissolved in dimethylformamide.

For ConA-blotting, the electrotransferred nitrocellulose membranes were washed with TBST and incubated for $30 \mathrm{~min}$ with $0.1 \mathrm{mg}$ ConA ml${ }^{-1}$ in TBST at room temperature. After washing three times with TBST, the membranes were immersed in a solution of horseradish peroxidase in TBST $\left(0 \cdot 1 \mathrm{mg} \mathrm{ml}^{-1}\right)$ at room temperature for $1 \mathrm{~h}$. Non-specifically bound peroxidase was washed away as before and ConAbound enzyme developed with $0.05 \%$ diaminobenzidine and $0.001 \% \mathrm{H}_{2} \mathrm{O}_{2}$ in $50 \mathrm{mM}$ sodium phosphate $\mathrm{pH} 7 \cdot 4$. Colour intensity was enhanced by including in the substrate solution
$0.03 \%$ cobalt chloride and $0.03 \%$ nickel ammonium sulphate as described by De Blas \& Cherwinski (1983).

Adherence inhibition assays. Inhibition of C. albicans adhesion to the different proteins tested was assayed on microtitre plates. The wells were coated with the corresponding protein as described above. ExtrAvidin-peroxidaselabelled cells dispersed in DPBS containing the indicated amount of soluble protein or sugar were then incubated with the immobilized proteins for $1 \mathrm{~h}$ at room temperature. Adhered cells were then measured as described above. Results are expressed as percentage $A_{492}$ of uninhibited wells. The sugars assayed were obtained from Sigma.

Statistical analysis. Statistical analysis (Student's $t$-test) was performed by the Graphpad Prism3 computer program. $P>$ 0.01 was used as the significance criterion.

\section{RESULTS}

\section{Adherence to ECM proteins}

In the absence of $\mathrm{Ca}^{2+}$ and $\mathrm{Mg}^{2+}$ ions (modified DPBS), C. albicans cells adhered to immobilized collagen IV $(23 \cdot 6 \pm 2 \cdot 2 \%$; mean \pm SD of two experiments performed in triplicate); however, adhesion was significantly increased $(31.0 \pm 2.6 \%)$ when the ions were present (DPBS). For comparison, adhesion to fibronectin and laminin was also analysed. As has already been described (Klotz, 1990), adherence to type IV collagen was greater than to fibronectin or laminin $(11.5 \pm 2.5$ and $8.9 \pm 1.2 \%$, respectively) in the absence of any divalent cation. However, in contrast to previous reports (Klotz et al., 1993), no significant cation-induced increase in the adherence to fibronectin or to laminin was detected under our assay conditions $(10.5 \pm 2.2$ and $9.0 \pm 1.8 \%$, respectively).

\section{Adherence to type IV collagen domains}

The results described above suggested the possibility of different adhesins in C. albicans recognizing type IV collagen. Therefore, the three distinct domains of the molecule were isolated and assayed for adhesion. LBM was selected as the starting material for the purification because type IV collagen accounts for $>90 \%$ of its weight (Kefalides \& Ohno, 1987). As can be seen in Fig. 1 , each preparation was clearly enriched in the corresponding domain. When adhesion was measured, each domain was recognized by the yeast cells but by different mechanisms (Fig. 2). The degree of adhesion to both the $7 \mathrm{~S}$ and the CC domains was very similar (Fig. 2a, b). However, adherence to the CC domain was independent of $\mathrm{Ca}^{2+}$ and $\mathrm{Mg}^{2+}$ ions whereas adherence to the $7 \mathrm{~S}$ domain was only observed when these cations were present. C. albicans yeast cells also adhered to the NC1 domain but at a lower percentage and, in contrast to the CC domain, the adhesion was increased to a certain extent by divalent cations (Fig. 2c). From these results it appears that the increased adherence to collagen IV induced by $\mathrm{Ca}^{2+}$ and $\mathrm{Mg}^{2+}$ ions is caused mainly by the cation-dependent adhesion of yeast cells to the $7 \mathrm{~S}$ domain and that different C. albicans adhesins interact with type IV collagen. 
(a)

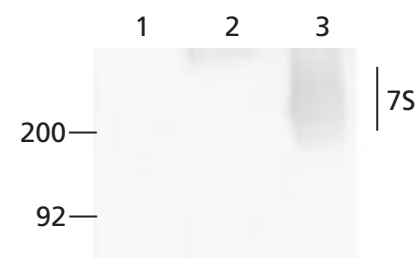

$69-$

$46-$

$30-$

$21-$ (b)

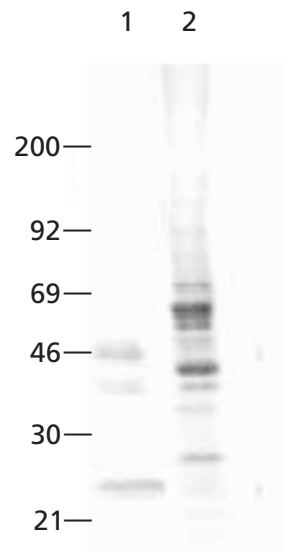

(c)

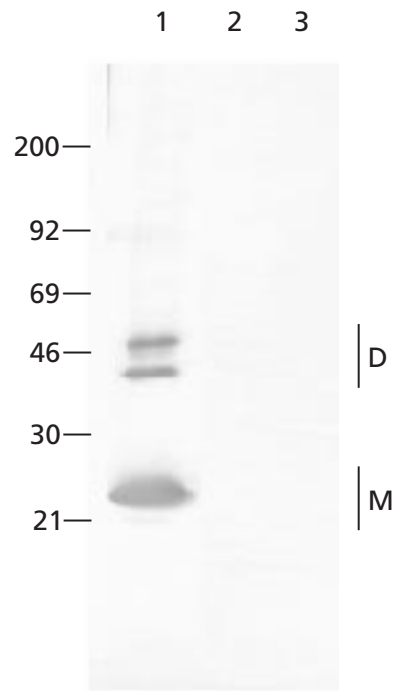

Fig. 1. Immunoblot analysis of the three main domains from bovine LBM type IV collagen. The three domains (10 $\mu \mathrm{g}$ protein) were subjected to SDS-PAGE and immunoblotted. Immunological detection was carried out with the following polyclonal antibodies: (a) anti-7S, antibody directed against the long-form N-terminal cross-linking domain (7S); (b) antitype IV, antibody directed against reduced and alkylated collagen IV; (c) anti-NC1, antibody directed against the $\alpha 1$ (IV) monomeric subunit of the NC1 domain. Lanes: 1, NC1 domain; 2, CC domain; 3, 7S domain. The positions of molecular mass markers and their size in $\mathrm{kDa}$ are indicated on the left. ' $\mathrm{D}$ ' and ' $\mathrm{M}$ ' indicate the dimeric and monomeric subunits of the NC1 domain, respectively.

Similar results were obtained using fluorescein-labelled, soluble domains and untreated cells in suspension, and measuring cell-bound fluorescence (data not shown)

The specificity of binding was tested by inhibiting adhesion to the immobilized domains with their soluble forms. As shown in Table 1, each domain inhibited the adhesion of C. albicans cells to its immobilized form. The CC domain caused some inhibition of the binding to both 7S and NC1 domains. These inhibitions could result, in the first case, from contamination of the CC preparation with $7 \mathrm{~S}$ because of inefficient digestion with pepsin, and, in the second case, from the sharing of common adhesins. In support of the latter possibility is the fact that adhesion to immobilized CC was also slightly inhibited by NC1 but not by 7S.

\section{Time course and cation-dependence of the adherence to $7 \mathrm{~S}$ domain}

Because of the absolute dependence on divalent cations for $C$. albicans binding to $7 \mathrm{~S}$, the effect of different amounts of $\mathrm{Ca}^{2+}$ and $\mathrm{Mg}^{2+}$ on this adhesion was studied. Addition of $\mathrm{CaCl}_{2}$ or $\mathrm{MgCl}_{2}$ to the assay increased yeast adhesion; the maximum was reached at lower $\mathrm{Mg}^{2+}$ than $\mathrm{Ca}^{2+}$ concentrations $(0.5 \mathrm{mM}$ and $1 \mathrm{mM}$, respectively) (Fig. 3a). DPBS containing approximately these cation concentrations was therefore used in subsequent studies. Addition of $5 \mathrm{mM}$ EDTA to DPBS completely abolished the adhesion to $7 \mathrm{~S}$ (data not shown).

The ability of C. albicans yeast phase to adhere to immobilized 7S as a function of time was also investigated and was maximal at 20 min (Fig. 3b).

\section{Effect of deglycosylation on the adherence to $7 \mathrm{~S}$ or to its subunits}

The requirement of a divalent cation for yeast cell adhesion to $7 \mathrm{~S}$ suggested the involvement of an integrinor a lectin-like adhesin. Moreover, the presence on this domain of the unique $N$-linked oligosaccharide chains of type IV collagen further supported the possibility of a lectin-like adhesin recognizing this complex sugar residue. To test this possibility, the $\mathrm{N}$-linked oligosaccharide residues of the $7 \mathrm{~S}$ domain were removed by digestion with $\mathrm{N}$-glycosidase F (Langeveld et al., 1991) and the adhesion to the deglycosylated domain was measured. The efficiency of $\mathrm{N}$-glycosidase $\mathrm{F}$ in releasing most of the oligosaccharide was deduced from the reduced ConA reactivity of the $7 \mathrm{~S}$ domain after enzyme treatment (Langeveld et al., 1991; Nayak \& Spiro, 1991). In parallel with the complex sugar removal, adhesion to deglycosylated $7 \mathrm{~S}$ was clearly diminished compared to untreated domain $(27 \pm 3.5 \%$ of the control value; mean $\pm \mathrm{SD}$ of five experiments performed in triplicate). This result pointed to the $\mathrm{N}$-linked sugar residue as a C. albicans receptor on the type IV collagen $7 \mathrm{~S}$ domain.

The chemical nature of the adhesin was tested by treatment of the intact yeast cells with trypsin before assaying their cation-dependent adherence to the $7 \mathrm{~S}$ domain. Trypsin incubation reduced yeast adherence to $20 \%$ and $30 \%$ of the buffer only and trypsin-heated control values, respectively, indicating the protein nature of the adhesin.

To further check the involvement of the $7 \mathrm{~S}$ sugar residue 

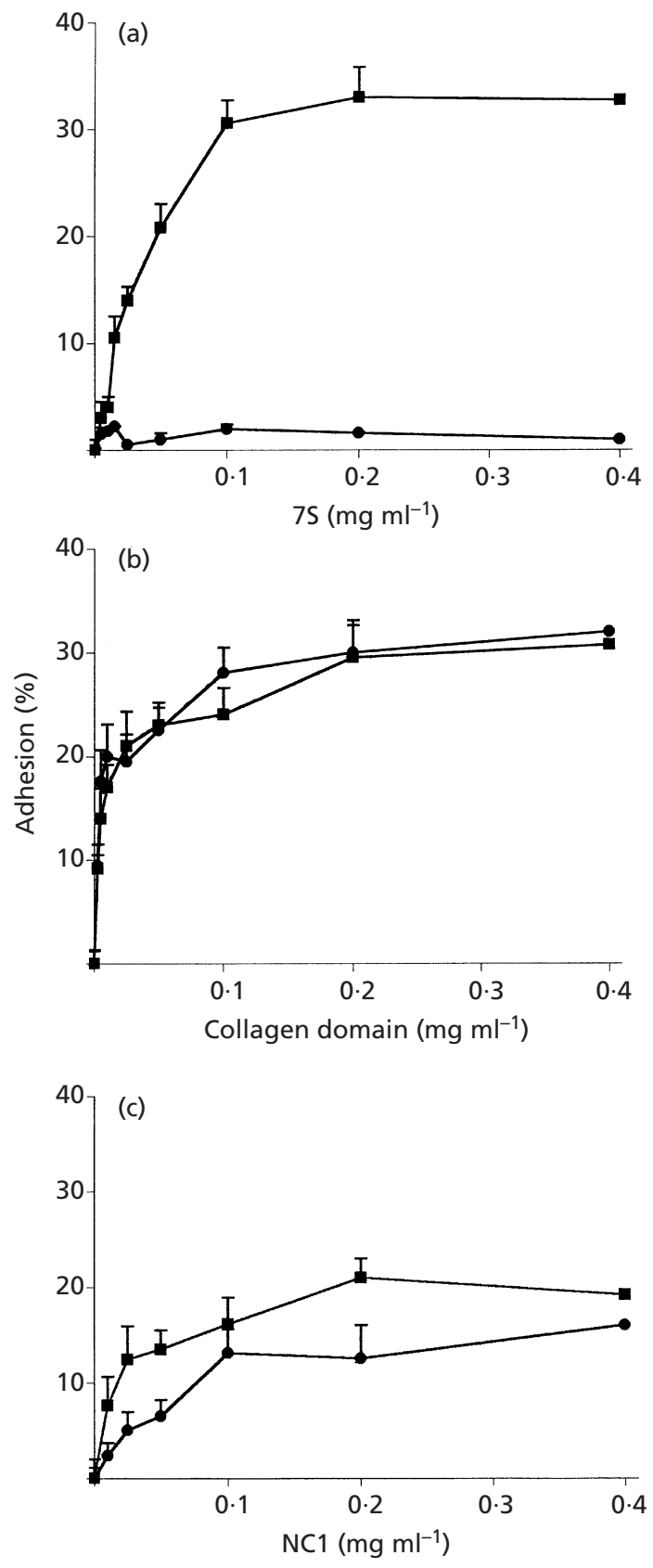

Fig. 2. Dose-response of $C$. albicans adhesion to collagen IV domains in the presence or absence of divalent cations. (a) $7 \mathrm{~S}$, (b) CC, (c) NC1. Microtitre plate wells were coated with $100 \mu \mathrm{l}$ of the indicated domain concentration and incubated with yeast cells resuspended in modified DPBS $(\boldsymbol{\theta})$ or in DPBS ( $\boldsymbol{\square})$. Percentage adhesion was determined as described in Methods. Results are means \pm SD of five separate experiments performed in triplicate.

and to rule out a concealment of other receptors by a deglycosylation-induced rearrangement of its subunits, the $7 \mathrm{~S}$ domain was reduced and its free thiol groups blocked with iodoacetamide. Two of its subunits were then isolated by preparative electrophoresis and their adhesion capacity was determined with and without
Table 1. Inhibition of $C$. albicans adherence to immobilized collagen IV domains by their soluble forms

Adhesion was measured and expressed as a percentage of the control value as described in Methods. Results are means \pm SD of three experiments performed in triplicate.

\begin{tabular}{|lccl|}
\hline Immobilized domain* & \multicolumn{3}{c|}{ Soluble domain $\dagger$} \\
\cline { 2 - 4 } & $7 S$ & CC & NC1 \\
\hline $7 S$ & $53 \pm 4$ & $78 \pm 12$ & $99 \pm 1$ \\
CC & $106 \pm 6$ & $27 \pm 4$ & $86 \pm 10$ \\
NC1 & $103 \pm 10$ & $62 \pm 6$ & $26 \pm 3$ \\
\hline
\end{tabular}

* Microtitre wells were coated with $40 \mu \mathrm{g}$ immobilized domain protein, except for $7 \mathrm{~S}$ where $10 \mu \mathrm{g}$ protein was used.

†The concentrations of the soluble domain proteins in the incubation medium were $0.8 \mathrm{mg} \mathrm{ml}^{-1}$.

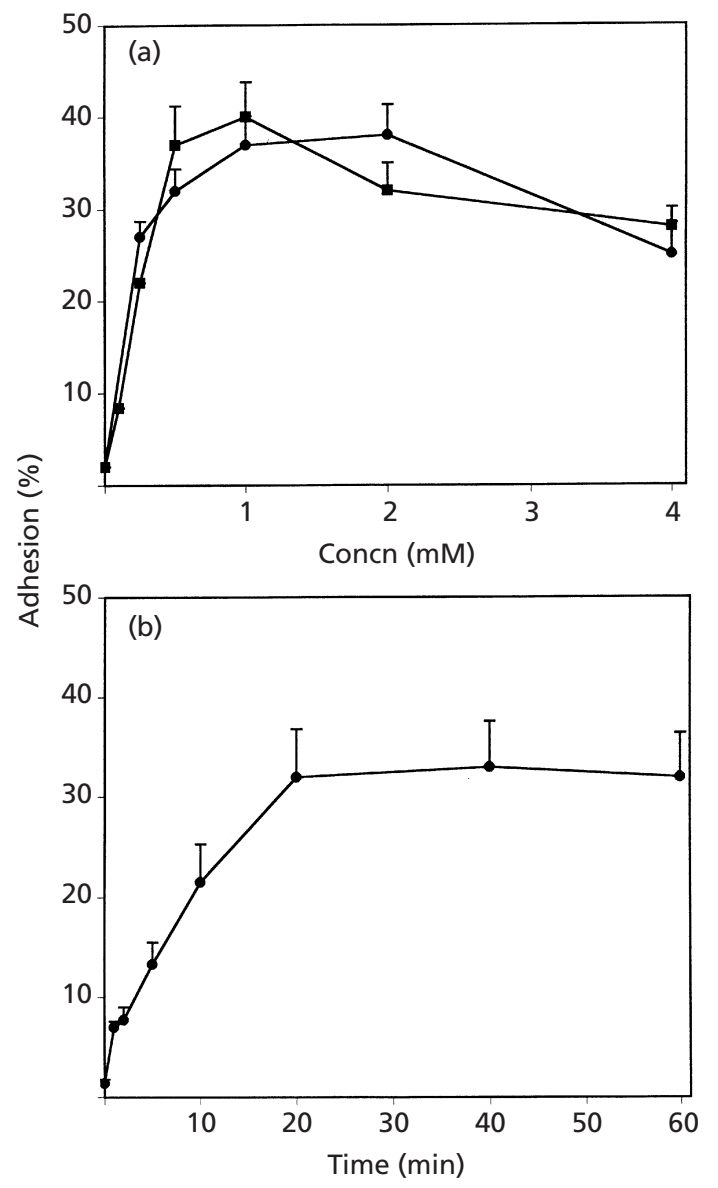

Fig. 3. Cation- and time-dependence of $C$. albicans adhesion to $7 S$ domain of collagen IV. (a) Effect of different $\mathrm{Ca}^{2+}(\mathbf{O})$ and $\mathrm{Mg}^{2+}$ ( $\square$ ) concentrations on adhesion. (b) Time course of adhesion in the presence of $1 \mathrm{mM} \mathrm{Ca}^{2+}$ and $0.5 \mathrm{mM} \mathrm{Mg} \mathrm{Mg}^{2+}$. Percentage adhesion was determined as described in Methods. Results are means \pm SD of two different experiments performed in triplicate. 

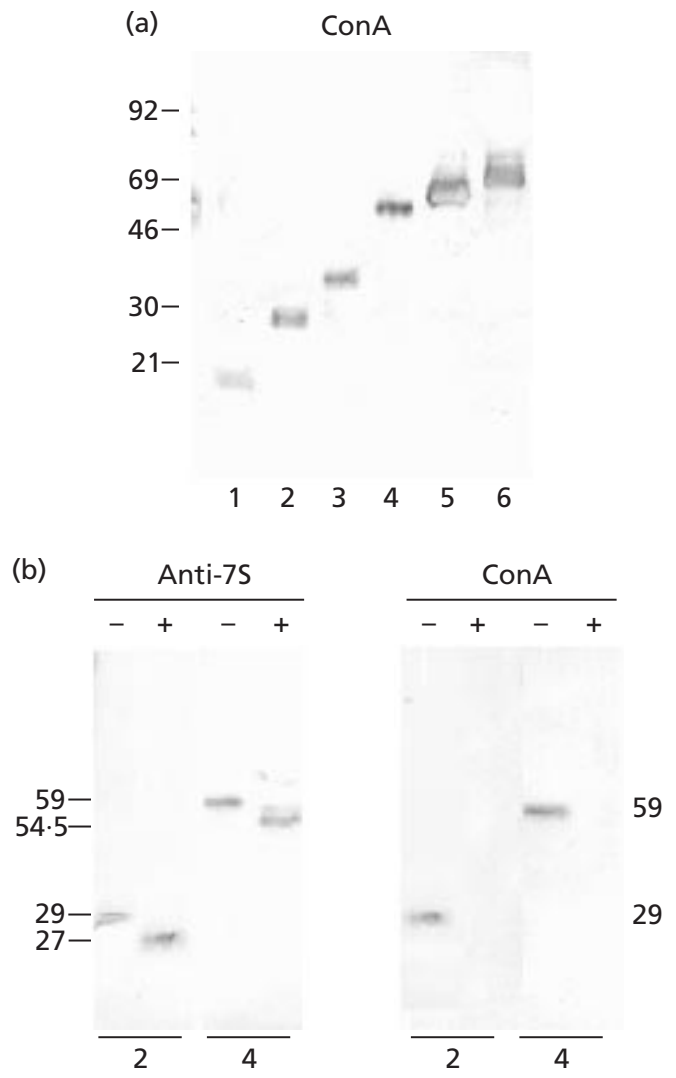

Fig. 4. ConA- and immuno-blotting of purified 75 subunits. (a) ConA-blotting of $7 \mathrm{~S}$ subunits isolated by preparative electrophoresis. Five micrograms of protein from pooled electrophoretic fractions was submitted to SDS-PAGE $(15 \%$ acrylamide gel), transferred to nitrocellulose paper and detected with ConA. Lanes 1-6 contain different electrophoretic fractions. Molecular mass markers (in kDa) are indicated on the left. (b) Immuno- and ConA-blotting of fractions 2 and 4 without $(-)$ and with $(+)$ previous $N$ glycosidase $F$ treatment. Aliquots from fractions 2 and 4 were incubated with buffer or with $\mathrm{N}$-glycosidase $\mathrm{F}$ and $5 \mu \mathrm{g}$ of each one, after SDS-PAGE and transfer to nitrocellulose paper, were probed with anti-7S antibody (anti-7S) and ConA. The calculated molecular masses of the subunits (in $\mathrm{kDa}$ ) are indicated on the left and right sides.

previous $\mathrm{N}$-glycosidase $\mathrm{F}$ treatment. As shown in Fig. 4(a), several subunits could be purified from carboxyamidomethylated $7 \mathrm{~S}$ by preparative electrophoresis. Two of them were chosen for adhesion studies because they were obtained in good yield and showed electrophoretic molecular masses of about 29 and $59 \mathrm{kDa}$, which could correspond to monomer (Nayak \& Spiro, 1991) and dimer, respectively. Both subunits reacted with anti-7S antibodies and ConA (Fig. 4b), indicating that they were part of the $7 \mathrm{~S}$ domain and carried the complex sugar residue. When assayed for adhesion, both polypeptides were recognized by C. albicans in the presence of $\mathrm{Ca}^{2+}$ and $\mathrm{Mg}^{2+}$. However, after removal of sugar residues, evidenced by the loss of reactivity with ConA but not with anti-7S antibodies (Fig. 4b), the cation-dependent adhesion to deglycosylated 29
Table 2. Effect of carbohydrates on the adhesion of C. albicans to the $7 \mathrm{~S}$ domain of type IV collagen

Adhesion is expressed as described in Methods. Results are means \pm SD of at least three experiments performed in triplicate. Microtitre wells were coated with $10 \mu \mathrm{g} 7 \mathrm{~S}$ domain.

\begin{tabular}{|lcc|}
\hline Carbohydrate & Concentration* & Adhesion $(\%)$ \\
\hline Galactose & $0 \cdot 02$ & $102 \pm 2$ \\
Glucose & $0 \cdot 20$ & $102 \pm 6$ \\
& $0 \cdot 02$ & $100 \pm 5$ \\
L-Fucose & $0 \cdot 20$ & $97 \pm 2$ \\
& $0 \cdot 02$ & $80 \pm 3$ \\
& $0 \cdot 10$ & $76 \pm 6$ \\
N-Acetylglucosamine & $0 \cdot 20$ & $64 \pm 8$ \\
& $0 \cdot 02$ & $93 \pm 6$ \\
& $0 \cdot 05$ & $85 \pm 3$ \\
& $0 \cdot 10$ & $74 \pm 5$ \\
Methylmannoside & $0 \cdot 20$ & $51 \pm 9$ \\
& $0 \cdot 02$ & $81 \pm 6$ \\
& $0 \cdot 10$ & $72 \pm 2$ \\
Lactose & $0 \cdot 20$ & $65 \pm 3$ \\
Maltose & $0 \cdot 02$ & $98 \pm 4$ \\
N-Acetyllactosamine & $0 \cdot 20$ & $96 \pm 2$ \\
& $0 \cdot 20$ & $107 \pm 4$ \\
& $0 \cdot 05$ & $74 \pm 5$ \\
& $0 \cdot 10$ & $59 \pm 5$ \\
& $0 \cdot 10$ & $100 \pm 1$ \\
& $1 \cdot 00$ & $94 \pm 2$ \\
\hline
\end{tabular}

*Expressed as molarity, except for heparan sulfate, which is expressed as $\mathrm{mg} \mathrm{ml}^{-1}$.

and $59 \mathrm{kDa}$ polypeptides decreased to $35 \pm 2.0$ and $40 \pm 3 \cdot 2 \%$ (mean \pm SD of two experiments performed in triplicate) of that to untreated polypeptides, respectively. After the deglycosylation process, the molecular masses of both subunits were reduced to about 27 and $54.5 \mathrm{kDa}$, respectively. The results confirmed the above suggestion of a lectin-like adhesin in C. albicans which interacts with the only complex sugar residue present on each $\alpha$ chain of the collagen IV molecule.

\section{Sugar specificity of the adherence to $7 \mathrm{~S}$}

The sugar specificity of the lectin-like adhesin interacting with the oligosaccharide residues of the $7 \mathrm{~S}$ domain was analysed by inhibiting yeast cell adhesion to the immobilized domain with different solution-phase sugars (Table 2 ). Adhesion was similarly reduced by Lfucose and methylmannoside (around 20\% and 40\% inhibition for the lower and higher concentrations, respectively). $\mathrm{N}$-Acetylglucosamine inhibited $\mathrm{C}$. albicans adherence by $50 \%$ at $0 \cdot 2 \mathrm{M}$ concentration. 
Inhibition was even higher with $\mathrm{N}$-acetyllactosamine since a $40 \%$ reduction in adhesion was again obtained, but at $0 \cdot 1 \mathrm{M}$ concentration. At this same concentration the inhibition induced by the monosaccharides was around $20-25 \%$, indicating that the greater the size of the sugar the greater the adhesion inhibition. When combinations of these monosaccharides were used as inhibitors, each one at a concentration $(0 \cdot 1 \mathrm{M})$ which separately resulted in only $20-25 \%$ adhesion reduction, the adherence decrease was not greater than the one obtained when tested individually. For example, Lfucose plus methylmannoside produced an adhesion inhibition of $25 \%$; this same combination plus $\mathrm{N}$ acetylglucosamine inhibited by $27 \%$, and both $\mathrm{L}$-fucose plus $\mathrm{N}$-acetylglucosamine or methylmannoside plus $\mathrm{N}$ acetylglucosamine reduced adhesion by about $30 \%$. These findings fit better with only one lectin recognizing the oligosaccharide residue than with different lectins interacting with its monosaccharide units. No inhibition was caused by the other sugars tested.

\section{DISCUSSION}

C. albicans is an opportunistic fungal pathogen that appears to be capable of employing several adhesins to mediate attachment to host receptors. Some of these receptors are part of the BM molecules and adherence to them represents a crucial step in the development of candidiasis (Cutler, 1991; Fukazawa \& Kagaya, 1997; Klotz, 1994). C. albicans has been shown to adhere to collagen IV, a major BM glycoprotein, with high affinity (Klotz, 1990; Yan et al., 1998). Other micro-organisms, such as A. fumigatus (Gil et al., 1996) and Helicobacter pylori (Trust et al., 1991), have also been reported to bind avidly to BM collagen. However, little information has been provided regarding the nature of the receptors involved in C. albicans-collagen IV interactions. The present study shows for the first time that C. albicans utilizes different adhesins to interact with type IV collagen and that the only oligosaccharide group of collagen IV chains is recognized by a lectin-like adhesin.

Adhesion of C. albicans to type IV collagen is increased by the divalent cations $\mathrm{Ca}^{2+}$ and $\mathrm{Mg}^{2+}$. A similar cationdependent adhesion has been described for other ECM proteins such as vitronectin (Spreghini et al., 1999), collagen I, gelatin or fibronectin (Klotz et al., 1993). However, in our hands no increase was observed with fibronectin as immobilized ligand. The discrepancy could result from the yeast strains used in the assays. Klotz et al. (1993) utilized clinical isolates whereas in our study a collection strain was assayed. It is possible that their clinical isolates expressed some integrin- or lectin-like adhesin which our strain did not. In this regard, strain-specific interactions of C. albicans lectins with several sugars have been found (Calderone \& Braun, 1991). Also, adhesion to immobilized laminin, another BM glycoprotein, was not affected by the presence of divalent cations. These results indicate that no cation-dependent integrin- or lectin-like adhesin is involved in the interaction of our C. albicans strain with laminin or fibronectin. López-Ribot et al. (1994) have described two polypeptides of 37 and $67 \mathrm{kDa}$ in wall extracts of C. albicans ATCC 26555 which bound laminin and cross-reacted with antibodies directed toward the human non-integrin laminin receptor. On the other hand, Negre et al. (1994) have also shown divalent cation- and Arg-Gly-Asp-peptide-independent interactions of fibronectin with another C. albicans collection strain, ATCC 44807.

In our study, divalent cations were necessary for adhesion of the yeast cells to the $7 \mathrm{~S}$ domain of type IV collagen; only partial cation-dependence appeared in the binding to the NC1 domain and there was no effect of these ions on the adhesion to the CC domain. Therefore, the calcium-dependent increase in the adherence of C. albicans to type IV collagen observed in our study is mainly accounted for by the interaction with the $7 \mathrm{~S}$ domain. This interaction appears to be due to a lectin-like adhesin since $N$-deglycosylation of the domain reduces the binding by about $70 \%$. The remaining adhesive capacity could result from incomplete deglycosylation as can be deduced from the diminished, but still present, ConA reactivity of the deglycosylated $7 \mathrm{~S}$ domain. Alternatively, other cation-dependent adhesins could also interact with this domain since there was also $\sim 40 \%$ adhesion to $\mathrm{N}$ deglycosylated $7 \mathrm{~S}$ subunits, where no ConA reactivity could be detected. In addition, these results show that the Asn-linked complex oligosaccharides of the $7 \mathrm{~S}$ domain are the sugar moieties recognized by the lectinlike adhesin of yeast cells. Each collagen IV $\alpha$ chain contains only one tri- or biantennary oligosaccharide group linked to an Asn residue within the $7 \mathrm{~S}$ region (Langeveld et al., 1991; Nayak \& Spiro, 1991). Consequently, the $7 \mathrm{~S}$ domain obtained from native LBM contains 12 Asn-linked sugar residues, one contributed by each subunit. The minimum and maximum sizes for this complex oligosaccharide, as deduced from the structure published by Langeveld et al. (1991), are about $1300 \mathrm{Da}$ and $2300 \mathrm{Da}$, respectively. These values are in agreement with the decrease in molecular mass $(2000 \mathrm{Da}$ and $4500 \mathrm{Da}$ ) observed after $\mathrm{N}$-deglycosylation of the $7 \mathrm{~S}$ monomeric and dimeric subunits, corroborating that complex oligosaccharide is the sugar removed by the $\mathrm{N}$ glycosidase F treatment.

It is noteworthy that we could not achieve more than $50 \%$ inhibition of the binding to immobilized $7 \mathrm{~S}$ with the soluble form even though its concentration was eight times higher than the one used for coating the microtitre wells. Similar findings have been already reported by others. Westerlund et al. (1991) observed a clear preference in P fimbriae of Escherichia coli for binding to immobilized fibronectin compared to the soluble form and Lowrance et al. (1988) showed also adherence of Streptococcus sanguis to immobilized fibronectin even in the presence of large concentrations of the molecule. On the other hand, Trust et al. (1991) found that the binding of laminin and type IV collagen to $H$. pylori was either irreversible or poorly reversible, obtaining only an $11 \%$ displacement of cell-bound laminin with the soluble molecule. Although an ir- 
reversible interaction cannot be excluded, our data seem to derive from conformational differences between the soluble and insoluble forms of the $7 \mathrm{~S}$ domain which result in the exposure of new adhesive motifs.

Further evidence for the lectin nature of the adhesin and for its sugar specificity was obtained from adhesion inhibition assays. Different sugars, including those reported to be part of the $7 \mathrm{~S}$ oligosaccharide chain, were used as inhibitors. This complex sugar occurs predominantly in the form of tri- and biantennary units with $\mathrm{N}$-acetyllactosamine residues in the branches, fucosylation of the innermost $\mathrm{N}$-acetylglucosamine (GlcNAc) residue of the $\mathrm{Man}_{3} \mathrm{GlcNAc}_{2}$ core and broad heterogeneity in the sugar residues at the non-reducing termini (Langeveld et al., 1991; Nayak \& Spiro, 1991). The oligosaccharides from bovine glomerular BM contain only one capping residue, in the form of either sialic acid or $\alpha$-D-galactose, whereas those from bovine LBM have only a single $\alpha$-D-galactose and no sialic acid; in contrast, human glomerular BM oligosaccharides are devoid of both sialic acid and $\alpha$-D-galactose (Nayak $\&$ Spiro, 1991). In our study, adhesion was inhibited only by L-fucose, methylmannoside, $\mathrm{N}$-acetylglucosamine and $\mathrm{N}$-acetyllactosamine. All these sugars are part of the $\mathrm{N}$-linked oligosaccharide. However, galactose, glucose and lactose, although also part of the oligosaccharide residue or of the hydroxylysine-linked disaccharide units, did not cause any significant inhibition.

Several lectin-like adhesins with different sugar specificities have been described in C. albicans (Brassart et al., 1991; Cameron \& Douglas, 1996; Critchley \& Douglas, 1987; Jimenez-Lucho et al., 1990; Ollert et al., 1993; Tosh \& Douglas, 1992; Yu et al., 1994). By overlaying glycosphingolipid chromatograms with labelled micro-organisms, Jimenez-Lucho et al. (1990) have described the adhesion of C. albicans and other fungi to lactosylceramide through its lactosyl moiety but not to glucosylceramide, indicating the requirement of an unsubstituted galactosyl residue for binding. The utilization by Candida of glycosphingolipids as cell receptors and the expression of fimbrial structures which mediate the interaction have also been reported by $\mathrm{Yu}$ et al. (1994). The fimbriae bound to synthetic $\beta$ GalNAc(1 $\rightarrow 4) \beta \mathrm{Gal}$-protein conjugates, asialo-GM1 and asialoGM2, but not to lactosylceramide. Neither of these adhesins seem to be the one interacting with the $7 \mathrm{~S}(\mathrm{IV})$ domain because neither lactose nor galatose inhibited Candida adhesion to the domain. On the basis of inhibition studies using sugars and lectins as blocking agents, Critchley \& Douglas (1987) showed that glycosides containing L-fucose, $\mathrm{N}$-acetyl-D-glucosamine and possibly D-mannose could all function as epithelial cell receptors for C. albicans. They proposed different adhesins for those glycosides. Brassart et al. (1991), employing carbohydrates extracted from human milk, demonstrated that the minimum structure required to inhibit yeast cell adherence to buccal epithelial cells was the disaccharide $\alpha \mathrm{Fuc}(1 \rightarrow 2) \beta \mathrm{Gal}$ found on all blood group substances of the ABO system. However, other structures related to the Lewis blood group system with the fucosyl group on a $\mathrm{N}$-acetylglucosamine residue and methylmannoside did not inhibit adherence. Since methylmannoside inhibited adhesion to $7 \mathrm{~S}$ (IV) and its fucose unit is bound to $\mathrm{N}$-acetylglucosamine, it does not seem probable that the same adhesin interacts with Fuc $\alpha 1 \rightarrow 2 \mathrm{Gal} \beta$ containing sugars and with $7 \mathrm{~S}(\mathrm{IV})$. More recently, Cameron \& Douglas (1996), using chromatogram overlay assays with glycolipids derived from human buccal epithelial cells and sheep erythrocytes, have indicated that glycolipids carrying blood group antigens can act as epithelial cell receptors for C. albicans. In this same work they also confirmed the previous results regarding the receptor specificity of C. albicans strains showing that some strains bound to glycosphingolipids carrying fucose or $\mathrm{N}$-acetylgalactosamine residues while others recognized those with $N$-acetylglucosamine. However, from their results, the possibility that the strain recognizing the $\mathrm{N}$-acetylglucosamine-containing receptors does bind also to those containing fucose cannot be excluded. As deduced from our sugar inhibition assays, adhesion to the $7 \mathrm{~S}$ (IV) domain was also mediated by its mannose, fucose and $\mathrm{N}$-acetylglucosamine residues. Curiously, when we tested mixtures of these monosaccharides at submaximal inhibition concentrations, the adhesion inhibition obtained was not significantly greater than that caused by the individual monosaccharides. If adhesion to the oligosaccharide was dependent on several adhesins, then additive inhibitions would be expected. Therefore, our results fit better with a single lectin binding to the $7 \mathrm{~S}$ oligosaccharide through several adhesive determinants than with several lectins interacting with the same oligosaccharide through specific sugar residues.

In summary, our results demonstrate the presence in $C$. albicans of a lectin-like adhesin which interacts with the only oligosaccharide chain of type IV collagen. With the data available, the possibility of this Candida lectin being coincident with one of those reported to recognize host cell-surface carbohydrates or other BM glycoproteins cannot be completely discarded. However, as discussed above, the analysis of all the available data is more in favour of it being a different one. In addition to this lectin, C. albicans possesses other adhesins which mediate its adherence to the BM ubiquitous collagen IV. Further studies are needed to characterize all these adhesins and to elucidate if, besides contributing to the establishment of Candida within the host tissues by anchoring the fungus to the BM, they induce differential responses in the micro-organism. They may also represent a good target for the design of new antifungal agents.

\section{ACKNOWLEDGEMENTS}

This work was supported by a grant from the Fondo de Investigación Sanitaria, Ministerio de Sanidad y Consumo, Spain. We thank Dr J. L. Mezquita and all the veterinarian staff of Mercavalencia for the kind supply of bovine eyes, and Dr E. Knecht for his critical comments and helpful suggestions. 


\section{REFERENCES}

Adini, A. \& Warburg, A. (1999). Interaction of Plasmodium gallinaceum ookinetes and oocysts with extracellular matrix proteins. Parasitology 119, 331-336.

Aitken, A. \& Learmonth, M. (1996). Carboxymethylation of cysteine using iodoacetamide/iodoacetic acid. In The Protein Protocols Handbook, pp. 339-340. Edited by J. M. Walker. Totowa, NJ: Humana Press.

Bejarano, P. A., Noelken, M. E., Suzuki, K., Hudson, B. G. \& Nagase, H. (1988). Degradation of basement membranes by human matrix metalloproteinase 3 (stromelysin). Biochem J 256, 413-419.

Bejarano, P. A., Langeveld, J. P. M., Hudson, B. G. \& Noelken, M. E. (1989). Degradation of basement membranes by Pseudomonas aeruginosa elastase. Infect Immun 57, 3783-3787.

Bouchara, J. P., Oumeziane, N. A., Lissitzky, J. C., Larcher, G., Tronchin, G. \& Chabasse, D. (1996). Attachment of spores of the human pathogenic fungus Rhizopus oryzae to extracellular matrix components. Eur J Cell Biol 70, 76-83.

Brassart, D., Woltz, A., Golliard, M. \& Neeser, J.-R. (1991). In vitro inhibition of adhesion of Candida albicans clinical isolates to human buccal epithelial cells by Fuc $\alpha 1 \rightarrow 2 \mathrm{Gal} \beta$-bearing complex carbohydrates. Infect Immun 59, 1605-1613.

Bromley, I. M. \& Donaldson, K. (1996). Binding of Aspergillus fumigatus spores to lung epithelial cells and basement membrane proteins: relevance to asthmatic lung. Thorax 51, 1203-1209.

Calderone, R. A. \& Braun, P. C. (1991). Adherence and receptor relationships of Candida albicans. Microbiol Rev 55, 1-20.

Cameron, B. J. \& Douglas, L. J. (1996). Blood group glycolipids as epithelial cell receptors for Candida albicans. Infect Immun 64, 891-896.

Chaffin, W. L., López-Ribot, J. L., Casanova, M., Gozalvo, D. \& Martinez, J. P. (1998). Cell wall and secreted proteins of Candida albicans: identification, function, and expression. Microbiol Mol Biol Rev 62, 130-180.

Critchley, I. A. \& Douglas, L. J. (1987). Role of glycosides as epithelial cell receptors for Candida albicans. J Gen Microbiol 133, 637-643.

Cutler, J. E. (1991). Putative virulence factors of Candida albicans. Annu Rev Microbiol 45, 187-218.

De Blas, A. L. \& Cherwinski, H. M. (1983). Detection of antigens on nitrocellulose paper immunoblots with monoclonal antibodies. Anal Biochem 133, 214-219.

Dickerson, S. K., Mathis, N. L., Rahman, M., Bergelson, J. M. \& Santoro, S. A. (1999). Determinants of ligand binding specificity of the $\alpha_{1} \beta_{1}$ and $\alpha_{2} \beta_{1}$ integrins. J Biol Chem 274, 32182-32191.

Fukazawa, Y. \& Kagaya, K. (1997). Molecular bases of adhesion of Candida albicans. J Med Vet Mycol 35, 87-99.

Gale, G., Finkel, D., Meinke, M., McClelland, M., Olson, J., Kendrick, K. \& Hostetter, M. (1996). Cloning and expression of a gene encoding an integrin-like protein in Candida albicans. Proc Natl Acad Sci U S A 93, 357-361.

Gil, M. L., Peñalver, M. C., López-Ribot, J. L., O’Connor, J. E. \& Martinez, J. P. (1996). Binding of extracellular matrix proteins to Aspergillus fumigatus conidia. Infect Immun 64, 5239-5247.

Hudson, B. G., Reeders, S. T. \& Tryggvason, K. (1993). Type IV collagen: structure, gene organization, and role in human diseases. J Biol Chem 268, 26033-26036.

Hudson, B. G., Gunwar, S., Chung, A. E. \& Burgeson, R. E. (1995). Matrix components (types IV and VII collagen, entactin and laminin) found in basement membranes. In Extracellular Matrix: a Practical Approach, pp. 99-129. Edited by M. A. Haralson \& J. R. Hussell. Oxford: IRL Press.

Jimenez-Lucho, V., Ginsburg, V. \& Krivan, H. C. (1990). Cryptococcus neoformans, Candida albicans, and other fungi bind specifically to the glycosphingolipid lactosylceramide (Gal/1-4Glc/1-1Cer), a possible adhesion receptor for yeasts. Infect Immun 58, 2085-2090.

Kefalides, N. A. \& Ohno, N. (1987). Heterogeneity in basement membranes. In Renal Basement Membrane in Health and Disease, pp. 81-97. Edited by R. G. Price \& B. G. Hudson. London: Academic Press.

Klotz, S. A. (1990). Adherence of Candida albicans to components of the subendothelial extracellular matrix. FEMS Microbiol Lett 68, 249-254.

Klotz, S. A. (1994). Plasma and extracellular matrix proteins mediate in the fate of Candida albicans in the human host. Med Hypotheses 42, 328-334.

Klotz, S. A., Rutten, M. J., Smith, R. L., Babcock, S. R. \& Cunningham, M. D. (1993). Adherence of Candida albicans to immobilized extracellular matrix proteins is mediated by calciumdependent surface glycoproteins. Microb Pathog 14, 133-147.

Klotz, S. A., Hein, R. C., Smith, R. L. \& Rouse, J. B. (1994). The fibronectin adhesin of Candida albicans. Infect Immun 62, 4679-4681.

Knight, C. G., Morton, L. F., Peachey, A. R., Tuckwell, D. S., Farndale, R. W. \& Barnes, M. J. (2000). The collagen-binding Adomains of integrins $\alpha_{1} \beta_{1}$ and $\alpha_{2} \beta_{1}$ recognize the same specific amino acid sequence, GFOGER, in native (triple-helical) collagens. J Biol Chem 275, 35-40.

Laemmli, U. K. (1970). Cleavage of structural proteins during the assembly of the head of bacteriophage T4. Nature 227, 680-685. Langeveld, J. P. M., Wieslander, J., Timoneda, J., McKinney, P., Butkowski, R. J., Wisdom, B. J. \& Hudson, B. G. (1988). Structural heterogeneity of the noncollagenous domain of basement membrane collagen. J Biol Chem 263, 10481-10488.

Langeveld, J.P. M., Noelken, M. E., Hard, K., Todd, P., Vliegenthart, J. F. G., Rouse, J. \& Hudson, B. G. (1991). Bovine glomerular basement membrane. Location and structure of the asparagine-linked oligosaccharide units and their potential role in the assembly of the 7S collagen IV tetramer. J Biol Chem 266, 2622-2631.

Lee, K. L., Buckley, H. R. \& Campbell, C. C. (1975). An amino acid liquid synthetic medium for development of mycelial and yeast forms of Candida albicans. Sabouradia 13, 148-153.

Linblom, A. \& Paulsson, M. (1996). Basement membranes. In Extracellular Matrix: Tissue Function, pp. 132-174. Edited by W. D. Comper. Amsterdam: Hardwood Academic Publishers.

López-Ribot, J. L., Casanova, M., Monteagudo, C., Sepúlveda, P. \& Martinez, J.P. (1994). Evidence for the presence of a highaffinity laminin receptor-like molecule on the surface of Candida albicans yeast cells. Infect Immun 62, 742-746.

Lowrance, J. H., Hasty, D. L. \& Simpson, W. A. (1988). Adherence of Streptococcus sanguis to conformationally specific determinants in fibronectin. Infect Immun 56, 2279-2285.

Martin, G. R. \& Timple, R. (1987). Laminin and other basement membrane components. Annu Rev Cell Biol 3, 57-85.

Nayak, B. R. \& Spiro, R. G. (1991). Localization and structure of the asparagine-linked oligosaccharides of type IV collagen from glomerular basement membrane and lens capsule. J Biol Chem 266, 13978-13987.

Nègre, E., Vogel, T., Levanon, A., Guy, R., Walsh, T. J. \& Roberts, D. D. (1994). The collagen binding domain of fibronectin contains 
a high affinity binding site for Candida albicans. J Biol Chem 269, 22039-22045.

Ogata, R. (1998). Type IV collagen and laminin enhance the motility, adhesion, and proliferation of hepatoma cells. Kurume Med J 45, 11-20.

Ollert, M. W., Söhnchen, R., Korting, H. C., Ollert, U., Bräutigam, S. \& Bräutigam, W. (1993). Mechanisms of adherence of Candida albicans to cultured human epidermal keratinocytes. Infect Immun 61, 4560-4568.

Peczon, B. D., McCarthy, C. A. \& Merritt, R. B. (1982). Probing the subunit structure of cow anterior lens capsule with the detergent, sodium dodecyl sulfate. Exp Eye Res 35, 643-651.

Peñalver, M. C., O'Connor, J. E., Martinez, J. P. \& Gil, M. L. (1996). Binding of human fibronectin to Aspergillus fumigatus conidia. Infect Immun 64, 1146-1153.

Penefsky, H. S. (1977). Reversible binding of Pi by beef heart mitochondrial adenosine triphosphatase. J Biol Chem 252, 2891-2899.

Petitclerc, E., Boutaud, A., Prestayko, A., Xu, J., Sado, Y., Ninomiya, Y., Sarras, M. P., Jr, Hudson, B. G. \& Brooks, P. C. (2000). New functions for non-collagenous domains of human collagen type IV. Novel integrin ligands inhibiting angiogenesis and tumour growth in vivo. J Biol Chem 275, 8051-8061.

Setty, S., Kim, Y., Fields, G. B., Clegg, D. O., Wayner, E. A. \& Tsilibary, E. C. (1998). Interactions of type IV collagen and its domains with human mesangial cells. J Biol Chem 273, 12244-12249.

Shahan, T. A., Ziaie, Z., Pasco, S., Fawzi, A., Bellon, G., Monboisse, J. C. \& Kefalides, N. A. (1999). Identification of CD47/integrinassociated protein and $\alpha \mathrm{v} \beta 3$ a two receptors for the alpha3(IV) chain of type IV collagen on tumour cells. Cancer Res 59, 4584-4590.

Smith, P. K., Krohn, R. I., Hermanson, G. T. \& 7 other authors (1985). Measurement of protein using bicinchoninic acid. Anal Biochem 150, 76-85.

Spiro, R. J. \& Fukushi, S. (1969). The lens capsule. Studies on the carbohydrate units. J Biol Chem 244, 2049-2058.

Spreghini, E., Gismondi, A., Piccoli, M. \& Santoni, G. (1999). Evidence for $\alpha \mathrm{v} \beta 3$ and $\alpha \mathrm{v} \beta 5$ integrin-like vitronectin (VN) receptors in Candida albicans and their involvement in yeast cell adhesion to VN. J Infect Dis 180, 156-166.

Sundstrom, P. (1999). Adhesins in Candida albicans. Curr Opin Microbiol 2, 353-357.

Toda, S., Matsumara, S., Yonemitsu, N., Fujitani, N., Terayama, K., Funatsumaru, S. \& Sugihara, H. (1995). Effects of various types of extracellular matrices on adhesion, proliferation, differentiation, and c-fos protein expression of porcine thyroid follicle cells. Cell Struct Funct 20, 345-354.

Tosh, F. D. \& Douglas, L. J. (1992). Characterization of a fucosidebinding adhesin of Candida albicans. Infect Immun 60, 4734-4739.

Towbin, H., Staehelin, T. \& Gordon, J. (1979). Electrophoretic transfer of proteins from polyacrylamide gels to nitrocellulose sheets: procedure and some applications. Proc Natl Acad Sci US A 76, 4350-4354.

Trust, T. J., Doig, P., Emody, L., Kienle, Z., Wadstrom, T. \& O'Toole, P. (1991). High-affinity binding of the basement membrane proteins collagen type IV and laminin to the gastric pathogen Helicobacter pylori. Infect Immun 59, 4398-4404.

Vázquez-Torres, A. \& Balish, E. (1997). Macrophages in resistance to candidiasis. Microbiol Mol Biol Rev 61, 170-192.

Westerlund, B., Van Die, I., Kramer, C. \& 8 other authors (1991). Multifunctional nature of $\mathrm{P}$ fimbriae of uropathogenic Escherichia coli: mutations in $f_{s o E}$ and $f_{s o F}$ influence fimbrial binding to renal tubuli and immobilized fibronectin. Mol Microbiol 5, 2965-2975.

Yan, S., Rodrigues, R. G., Cahn-Hidalgo, D., Walsh, T. J. \& Roberts, D. D. (1998). Hemoglobin induces binding of several extracellular matrix proteins to Candida albicans. Identification of a common receptor for fibronectin, fibrinogen and laminin. J Biol Chem 273, 5638-5644.

Yu, L., Lee, K. K., Sheth, H. B., Lane-Bell, P., Srivastava, G., Hindsgaul, O., Paranchych, W., Hodges, R. S. \& Irvin, R. T. (1994). Fimbria-mediated adherence of Candida albicans to glycosphingolipid receptors on human buccal epithelial cells. Infect Immun 62, 2843-2848.

Received 30 October 2000; revised 5 March 2001; accepted 14 March 2001. 